* Pós-Doutor em Direito Civil, com bolsa de pesquisa PNPD/ CAPES, na Universidade do Vale do Rio dos Sinos - UNISINOS (2014). Doutor em Direito Civil na Universidade Federal do Rio Grande do Sul - UFRGS (2013). Mestre em Ciências Criminais pela Pontifícia Universidade Católica do Rio Grande do Sul - PUCRS (2007). Especialista em Ciências Penais pela PUCRS (2005). Pós-graduação pela Escola da Magistratura do Rio Grande do Sul - AJURIS (2003). Graduado em Ciências Jurídicas e Sociais pela PUCRS (2002). Professor da Graduação e Pós-Graduação da Faculdade de Direito da Universidade do Extremo Sul Catarinense e da Pós-graduação do Centro Universitário Ritter dos Reis - Uniritter. E-mail: gustavoborges@hotmail.com.

** Mestre em Odontologia pela PUCRS. Aluna do Curso de graduação em Direito da Fundação Escola Superior do Ministério Público.

E-mail: rwmottin@gmail.com

\section{Erro Médico E Consentimento \\ Informado: Panorama \\ JURISPRUDENCIAL Do TJRS E Do STJ}

\author{
Medical Malpractice AND Informed \\ CONSENT: JURISPRUDENTIAL OVERVIEW OF \\ TJRS AND STJ
}

Gustavo Silveira Borges*

Roberta Weirich Mottin**

Como citar: BORGES, Gustavo Silveira. MOTTIN, Roberta Weirich. Erro médico e consentimento informado: panorama jurisprudencial do TJRS e do STJ. Revista do Direito Público, Londrina, v. 12 , n. 1, p.15-47, abr. 2017. DOI: 10.5433/24122-107817-1X.2017v17n1p15. ISSN: $1980-511 \mathrm{X}$.

Resumo: O consentimento informado é um processo de informação e deliberação visando à aceitação do paciente a um determinado tratamento médico. É visto hoje como instrumento da bioética para o fortalecimento da relação médico paciente. O objetivo desse trabalho é investigar em que medida o consentimento informado pode ser útil a fim de evitar demandas judiciais contra médicos, bem como determinar o estatuto jurídico aplicável, que fundamenta a sua necessidade. Para isso, realizou-se pesquisa doutrinária $\mathrm{e}$ jurisprudencial a respeito do tema, no âmbito do TJRS e STJ. 
Palavras-chave: Consentimento informado. Erro médico. Paciente. Consumidor. Jurisprudência.

Abstract: A patient gives informed consent, which is composed of information and previous deliberation, to medical professionals for a specific treatment. In addition, informed consent is also a bioethical instrument used for strengthening doctor-patient relationships. Furthermore, this paper investigates the usefulness of informed consents. Nonetheless, it is a helpful tool for avoiding lawsuits and aids in determining the applicable rule of law. Moreover, this study used law books and the TJRS and STJ case studies.

Keywords: Informed consent. Medical malpractice. Patients. Consumers. Case studies. 


\section{INTRODUÇÃO}

A partir do século XX houve enormes mudanças na área da saúde, notadamente nas ciências biomédicas e tecnológicas, que possibilitaram o surgimento de inúmeras novidades de intervenções nessas áreas. A constante aceleração e as inovações tecnológicas da sociedade produziram novos conceitos em vários setores, mais detidamente na Medicina.

No mesmo caminho, a relação médico-paciente tem passado por profundas transformações nos últimos anos. Transmudou-se de uma postura paternalista e centrada no conhecimento e nas decisões do médico para uma relação interpessoal e de diálogo, que aproxima o paciente do galeno.

Desse modo, a Bioética, como norteadora de uma nova visão da relação médico-paciente, apresenta o consentimento informado como instrumento de um processo de comunicação recíproca entre médico e paciente, no qual fazem parte as informações sobre riscos e benefícios que médicos devem prover aos pacientes, para que estes possam decidir autonomamente se querem ou não se submeter a determinado tratamento ou procedimento diagnóstico (PITHAN, 2012, p. 87).

Tais questões da presença do consentimento informado na relação médico-paciente têm batido as portas do Poder Judiciário a partir de demandas envolvendo responsabilidade civil por erro médico, o que merece reflexão.

Desta maneira, tais reflexões têm com o objetivo responder as seguintes indagações: Qual são os principais fundamentos da responsabilidade civil por erro médico por ausência de consentimento informado? A bioética, como instrumento de releitura da relação 
médico-paciente, pode auxiliar na diminuição de demandas, através do consentimento informado? Qual o atual posicionamento do Tribunal de Justiçca do Rio Grande do Sul e do Superior Tribunal de Justiça sobre a questão?

O presente ensaio é relevante porque se trata de uma preocupação que pulsa na sociedade contemporânea, qual seja a de se propiciarem meios para que forneça uma tutela eficaz das pessoas que tem direito do acesso à saúde.

\section{A RESPNSABILIDADE CIVIL MÉDICA EO CONSENTIMENTO INFORMADO NA RELAÇÃO MÉDICO- PACIENTE}

Desde os primórdios da humanidade, a saúde é alvo de atenção social no sentido de se combaterem os males inerentes e que afligem a própria condição humana. Porém, por muito tempo, o ser humano não se ocupou com o estudo das doenças, eis que voltado unicamente para a busca da cura.

Hipócrates - identificado até hoje como pai da medicina ocidental - revolucionou a história médica ao enfatizar a separação entre ciência e crendice, além de estabelecer tratados clínicos que possibilitaram o diagnóstico de uma série de doenças. Também ajudou a estabelecer uma ética própria para os que trilhavam o caminho da medicina através do conhecido Juramento de Hipócrates - proferido pelos médicos ao se formarem na universidade e que tange à responsabilidade social e humana do exercício da medicina em todas as suas formas (NESRALLA; PRATES, 2014, p. 13).

Há diversos relatos, no início do século XX, descrevendo 
situações de procedimentos médicos realizados mesmo contra a vontade dos pacientes. Mais tarde, devido a uma maior divulgação dos conhecimentos médicos na modernidade 1 (GAUER, 2006), bem como a conscientização dos indivíduos com relação a seus direitos fundamentais - dentre eles o direito à vida e autonomia privada - passou a vigorar a ideia de que o paciente deve decidir o que é melhor para ele (SOUZA, 2008, p. 77).

A velocidade dos avanços científicos e tecnológicos nas últimas décadas, especialmente nas áreas da medicina e da biologia, com implicações que afetam diretamente o ser humano, impõem uma necessária reflexão relativamente ao comportamento dos profissionais da atividade médica frente a novas situações surgidas envolvendo questões como a vida e a saúde e, principalmente, uma reflexão sobre a relação médico-paciente (BORGES, 2014, p. 80).

Com a chegada do século XXI, já na Pós-Modernidade ${ }^{2}$, ganhou força a preocupação em humanizar e democratizar a relação médicopaciente. Movimento este que valoriza a dignidade da pessoa humana, levando a medicina a repensar o vínculo de submissão do paciente a todas as decisões do seu médico. Passa-se a reconhecer a autonomia do enfermo, protegida não apenas por normas éticas, mas também pelo Direito (SGRECCIA, 2002, p. 13).

1 Explica GAUER, falando sobre a nova cosmovisão, que "na modernidade, a vinculação do conhecimento ao modelo galilaico-newtoniano e a consideração da ciência como campo privilegiado para a revelação da verdade fundam a matriz de conhecimento mais relevante da tradição ocidental moderna" (GAUER, 2006, p. 198).

2 Adotamos o termo Pós-Modernidade neste trabalho, conforme Zigmunt Bauman (1998), dentre outros, muito embora seja importante destacar, como coloca Hall (2005) que outros autores se utilizam de outras expressões conhecidas para tratar da questão, como: Modernidade Tardia (STUART HALL), Segundo Estágio Moderno (BECK, 1998), Estágio Final Moderno (GIDDENS), Supramoderno (BALANDIER), mas cientes de que, como refere Bhabha (2005), não há uma superação ou progresso em direção ao paraíso terrestre. 


\subsection{Tratamento Jurídico no Direito Brasileiro da Responsabilidade Civil Médica}

A reponsabilidade civil é um dever jurídico sucessivo, que decorre da violação de uma obrigação. O profissional, ao prestar um serviço, assume uma obrigação, ou seja, um dever jurídico originário, surgindo a partir daí a responsabilidade, que consiste no dever de compor o prejuízo causado pelo não cumprimento da obrigação (CAVALIERI FILHO, 2014, p. 2).

A responsabilidade civil é imposta a todo indivíduo que, por sua conduta lesiva, causar dano a outrem e tem por finalidade reprimir o dano privado e restabelecer o equilíbrio individual alterado, visando a uma convivência social pacífica. (BORGES, 2014, p. 211).

A responsabilidade civil médica, então, pode ser considerada como violação de um dever jurídico originário, que configura o ilícito e resulta em dano injusto a outra pessoa. Havendo relação de causalidade entre a ação e o dano sofrido, poderá ter caráter patrimonial ou extrapatrimonial (AGUIAR JUNIOR, 1997, p. 122).

O papel do médico não é estritamente técnico, mas que este se coloca também numa posição de conselheiro e protetor do enfermo, teria a assistência médica a natureza de contrato sui generis e não de mera locação de serviços.

A responsabilidade civil pelo ato médico tem natureza contratual, decorrente do adimplemento, do inadimplemento ou do mau adimplemento de um contrato de prestação de serviços médicos, cujo marco inicial seria a primeira consulta (SOTTO, 2003).

A relação médico-paciente é contratual quando resulta de um negócio jurídico prévio, ainda que tácito, entre médico e paciente, 
restringindo-se às questões relativas à medicina privada. No entanto, será extracontratual quando decorrer de atendimento médico de urgência ou emergência, sem o prévio consentimento do paciente, ou quando houver a prestação de serviço médico no setor público (AGUIAR JUNIOR, 1997, p. 123). A responsabilidade contratual decorre de um contrato ajustado livremente e de boa-fé, entre paciente e médico, conforme previsão dos artigos 389 a 400 do $\mathrm{CC} / 02$, que determina questões como o adimplemento e a mora decorrentes das declarações de vontade.

Não há de se falar em relação contratual entre médico e paciente, como modalidade de negócio jurídico. A autora situa tal relação sob os ditames do Código de Defesa do Consumidor, tendo em vista que a prestação de serviços médicos se insere no âmbito das relações de consumo (GOGLIANO, 2009, p. 509).

A controvérsia acerca do regime aplicável à responsabilidade civil médica (se contratual ou extracontratual), se de meios ou de resultados, perdeu força com a entrada em vigor do $\mathrm{CC} / 02$. A prestação de serviços realizada por profissional liberal diretamente ao paciente, implicará responsabilidade civil subjetiva, com base na análise da culpa, já que o artigo 195 do CC/02 explicita suas modalidades: negligência, imprudência ou imperícia (BENJAMIN; MARQUES, 2012, p. 174).

$\mathrm{O}$ art. 14 do CDC trata da responsabilidade do fornecedor de serviços, independentemente de culpa, por danos causados aos consumidores, em razão da prestação defeituosa do serviço. Entretanto, o parágrafo $4^{\circ}$ do mesmo artigo traz uma exceção ao princípio da objetivação da responsabilidade civil, determinando que a responsabilidade dos profissionais liberais (dentre eles o médico) deverá ser apurada mediante verificação de culpa. Marques, ao referir-se a tal exceção, afirma que: "[...] aqui privilegiado não é o serviço, mas a pessoa do profissional 
liberal[...]" (MARQUES, 2010, p. 289). Tal diversidade de tratamento explica-se em virtude da natureza intuitu personae dos serviços prestados por profissionais liberais. $\mathrm{O}$ dolo representa uma violação deliberada, consciente, intencional de um dever jurídico. Por outro lado, na culpa, o agente não visa causar prejuízo à vítima, mas de sua atitude negligente, imprudente ou imperita resulta dano a outrem (KFOURI NETO, 2013, p. 68).

Em regra, o devedor (profissional liberal) tem o ônus da prova da inocorrência da culpa, cabendo ao paciente (credor) comprovar apenas a existência de contrato, o inadimplemento, o dano sofrido e o nexo causal. Entretanto, se extracontratual, o ônus da prova da ocorrência da culpa é do demandante (paciente) (BORGES, 2014, p. 216).

Mesmo diante da responsabilidade subjetiva dos profissionais liberais, é possível inverter o ônus da prova, conforme artigo $6^{\circ}$ do CDC. Se, por um lado, o profissional liberal tem a garantia de que só responderá se for demonstrada sua culpa, de outro, poderá ser compelido a comprovar a não ocorrência deste fator subjetivo (NEVES, 2009, p. 63).

Entretanto, não basta a simples comprovação da culpa; deve-se evidenciar também o nexo causal, que liga o dano à conduta do agente. No entanto, o reconhecimento do nexo de causalidade não é tarefa fácil. Na medicina, dois pacientes acometidos pela mesma doença podem ser tratados de forma idêntica e virem a apresentar reações distintas à terapia, podendo em um caso haver a cura e, em outro, o agravamento da doença - ou até mesmo a morte (CLOTET, 2005). Haverá exclusão do nexo de causalidade entre o ato médico e o dano causado se este for provocado por culpa exclusiva do paciente, por inobservância a recomendações médicas - muitas vezes indispensáveis para efetivação da cura. O êxito de um tratamento, conforme a natureza da doença, poderá depender da 
disciplina do paciente ou seus responsáveis em relação às prescrições e recomendações do galeno (FARAH, 2010, 140).

No direito brasileiro, a responsabilidade civil do médico recebe o mesmo tratamento da responsabilidade civil em geral. Está prevista nos arts. 186 e 187 combinados com o art. 927, caput do CC/02. Em matéria de responsabilidade civil médica, há um dispositivo específico no art. 951, que prevê que:

O disposto nos arts. 948, 949 e 950 aplica-se ainda no caso de indenização devida por aquele que, no exercício de atividade profissional, por negligência, imprudência ou imperícia, causar a morte do paciente, agravar-lhe o mal, causar-lhe lesão, ou inabilitá-lo para o trabalho (BRASIL, 2002a).

Ao vínculo jurídico entre médico (fornecedor de serviços) e paciente (consumidor final) aplica-se o estatuto do Código de Defesa do Consumidor (CDC). No que tange à responsabilidade civil dos profissionais liberais, incidirá o art. 14 , parágrafo $4^{\circ}$ do $\mathrm{CDC}$, que exige análise da culpa.

Art. 14. O fornecedor de serviços responde, independentemente da existência de culpa, pela reparação dos danos causados aos consumidores por defeitos relativos à prestação dos serviços, bem como por informações insuficientes ou inadequadas sobre sua fruição e riscos $[\ldots] \S 4^{\circ} \mathrm{A}$ responsabilidade pessoal dos profissionais liberais será apurada mediante a verificação de culpa (BRASIL, 1990).

Analisado o tratamento jurídico da responsabilidade civil médica no direito brasileiro, e diante da atual promoção dos direitos civis dos pacientes, considerados hoje agentes ativos e com autonomia 
decisória no atendimento médico, justifica-se a necessidade de investigar em que medida o consentimento informado pode ser útil a fim de evitar demandas judiciais contra médicos.

A cirurgia se resume ao ato cirúrgico de intervenção no corpo do paciente, enquanto o tratamento é o conjunto de cuidados e medicações empregadas para manter ou melhorar a saúde do paciente. Já o pós-operatório consiste no momento imediatamente posterior ao encerramento da cirurgia até a alta hospitalar (GARFINKEL, 2007, p. 50).

$\mathrm{O}$ erro médico seria um resultado adverso decorrente de ação ou omissão do profissional por inobservância dos deveres jurídicos essenciais exigidos na atuação médica. Para o autor, devem ser excluídas desse conceito, entretanto, as limitações impostas pela própria natureza da doença, bem como as lesões produzidas deliberadamente pelo médico para tratar um mal maior.

Para fins deste estudo, o erro médico será tratado como uma falha cometida com culpa pelo profissional, em uma das modalidades: negligência, imprudência ou imperícia e que causa um resultado prejudicial ao paciente, podendo até mesmo resultar na sua morte.

\subsection{O Consentimento Informado como Instrumento da Bioética para o Fortalecimento da Relação Médico Paciente}

A constatação dos impactos da tecnologia sobre o homem, seu corpo e sua integridade abriu campo de investigação para o biodireito, o qual tem suas raízes nas reflexões suscitadas pelas terríveis experimentações científicas realizadas com seres humanos durante a Segunda Guerra. É nesse âmbito do biodireito que surge a problemática do consentimento livre e esclarecido, ou informado, como instrumento 
de promoção e proteção da pessoa humana, perante a atividade técnicocientífica (MACHADO, 2009).

A relação entre bioética e direito é tratada na doutrina por diversos autores, como Martins-Costa que refere que: "[...] diferentemente do que ocorria no passado, hoje o Direito não é visto tão só como ciência, mas, fundamentalmente como prudência, como arte prudencial que está inter-relacionada com as demais instâncias componentes do todo social, notadamente a ética [...]" (MARTINS-COSTA, 2000, p. 230).

A bioética é um campo de estudos que busca estabelecer o equilíbrio entre o avanço científico e os valores humanos. Para tal objetivo, de acordo com sua corrente principialista, orienta para a aplicação na prática profissional de quatro princípios básicos: a beneficência, a não maleficência, a autonomia e a justiça (BARBOZA, 2000).

Atualmente, a bioética apresenta o consentimento informado como instrumento de um processo de comunicação recíproca entre médico e paciente, contendo as informações sobre riscos e benefícios que médicos devem prover aos pacientes, para que estes possam decidir autonomamente se querem ou não se submeter a determinado tratamento ou procedimento diagnóstico (GOLDIM, 2002, p. 110). O consentimento informado é uma condição indispensável da relação médico-paciente. Trata-se de uma decisão voluntária, realizada por uma pessoa autônoma e capaz, tomada após um processo informativo e deliberativo, visando a aceitação de um tratamento específico, sabendo da natureza do mesmo, das suas consequências e dos seus riscos (CLOTET, 1995, p. 52). É um documento que evidencia tanto o cumprimento do dever do médico de informar, quanto a compreensão do paciente em relação ao seu estado de saúde e a anuência deste em relação aos procedimentos propostos, bem como do conhecimento dos riscos e complicações envolvidos. 
Para que tal consentimento seja eficaz, este deverá pressupor a assimilação das informações pelo paciente. Para isto, o médico deverá explicar detalhadamente as vantagens e desvantagens de um tratamento ou procedimento médico, verificando se o paciente compreende tais informações (NEVES, 2009, p. 76). De acordo com a bioética, o consentimento informado é um processo, e não a simples assinatura de um termo. Este processo resulta da relação de confiança estabelecida entre o médico e o paciente, podendo ou não vir acompanhado de um termo, denominado de "termo de consentimento informado". Um prontuário médico bem elaborado, que contenha todo o histórico do paciente, bem como os procedimentos realizados, servirá também como prova em eventual defesa (PITHAN, 2005).

A intermediação promovida pela bioética aproximou médicos e pacientes e, atualmente, o respeito à integridade, à liberdade, à confidencialidade e à dignidade da pessoa humana são inalienáveis e fazem parte do trabalho diário de quem exerce a medicina. Tais princípios, também informadores do consentimento esclarecido, visam preservar o paciente em sua totalidade, equilibrando o vínculo e conferindo-lhe garantias mínimas, não apenas quanto à relação jurídica desenvolvida entre médico e paciente, mas também quanto à proteção dos dados fornecidos em consultas e exames clínicos (COSTA; PESSINI, 2004, p. 189).

No Brasil, não há leis específicas que tratem do consentimento informado. Porém, há várias normas gerais do ordenamento jurídico que tratam indiretamente do assunto e permitem afirmar que há fundamentação legal de sua exigência no país.

A ausência de previsão legal do consentimento informado em nosso ordenamento jurídico não significa que tal requisito não seja 
importante, pois vem sendo reafirmado pela doutrina e jurisprudência, bem como pelo Código de Ética Médica. Embora o termo não venha expresso no Código Civil de 2002, o art. $15^{\circ}$ fundamenta sua exigência, ao afirmar que ninguém poderá ser constrangido a submeter-se com risco de vida, a tratamento médico ou intervenção cirúrgica (BRASIL, 2002a).

No Direito Civil, fala-se em dever de informar, que consiste no dever do prestador de serviço médico de informar o paciente sobre o serviço que lhe será prestado, de forma clara e específica. Tal conduta resulta do princípio da boa-fé subjetiva, que se traduz na cooperação, na lealdade, na transparência, na correção, na probidade e na confiança que devem existir na relação médico paciente. Somente a informação completa, precisa e adequada permite o consentimento informado.

$\mathrm{O}$ princípio da autonomia da vontade, positivado no $\mathrm{CC} / 02$, nos artigos 13 e 14, garante à pessoa humana o direito de dispor sobre o próprio corpo. A partir de tal princípio, decorre a necessidade de autorização prévia por parte do paciente, para que sejam realizados procedimentos em seu corpo. Pertencerá ao paciente a ponderação sobre os procedimentos, riscos, desconfortos e benefícios do tratamento a que será submetido, através dos esclarecimentos fornecidos pelo profissional.

O Código Civil de 2002, no seu artigo 186 trata da responsabilidade civil de todo indivíduo, ao aduzir que: “Aquele que, por ação ou omissão voluntária, negligência ou imprudência, violar direito e causar dano a outrem, ainda que exclusivamente moral, comete ato ilícito” (BRASIL, 2002a). O artigo 187 acrescenta: "Comete ato ilícito o titular de um direito que, ao exercê-lo, excede manifestamente os limites impostos pelo seu fim econômico e social, pela boa fé ou pelos bons costumes" (BRASIL, 2002a), lembrando que a medicina tem acima de tudo a finalidade da função social e o que caracteriza a natureza do homem é 
a sua humanidade (GOGLIANO, 2009, p. 513). Ademais, o artigo 927 do mesmo diploma legal prevê a reparação de danos causados por ato ilícito (PITHAN, 2005). O ato ilícito aqui considerado como fonte de obrigação, pois gera o dever de reparar o prejuízo. Tal norma disciplina a responsabilidade subjetiva, denominada extracontratual e nasce com a conduta que contraria o direito, ou seja, violação do dever genérico de conduta.

O consentimento informado tem base constitucional, porque está fundamentado por princípios como o da dignidade da pessoa humana, direito à vida, à liberdade, à igualdade, à privacidade e ao sigilo das informações. A autora também relaciona os referidos princípios constitucionais aos princípios da bioética. Além disso, infere que o art. 43 do Código de Defesa do Consumidor (CDC) garante ao pacienteconsumidor o acesso a todo conteúdo de fichas e cadastros que tragam informações sobre a sua pessoa (BAÚ, 2000).

O Código de Defesa do Consumidor, em diversos dispositivos legais (arts. $4^{\circ}, 6^{\circ}, 8^{\circ}$ e $9^{\circ}$ ) positiva o direito à informação clara e adequada durante todas as fases da relação de consumo entre médico, hospital e paciente (aqui considerado consumidor final), fornecendo informações quanto ao diagnóstico e prognóstico, possibilitando a aceitação ou não do tratamento proposto (MARQUES, 2010, p. 289).

O CDC, em seu artigo $6^{\circ}$, inciso III, aborda a necessidade de ser informado o consumidor de serviços (e o serviço médico-hospitalar é um desses serviços prestados ao consumidor) (SOUZA, 2008, p. 77). Ademais, o artigo 31 do mesmo código afirma que:

A oferta e apresentação de produtos ou serviços devem assegurar informações corretas, claras, precisas, ostensivas e em língua portuguesa [...], 
bem como sobre os riscos que apresentam à saúde e segurança dos consumidores" e o art. 39, também do CDC traz que: "É vedado ao fornecedor de produtos ou serviços dentre outras práticas abusivas: [...] VI- executar serviços sem a prévia elaboração de orçamento e autorização expressa do consumidor. (BRASIL, 1990)

O dever de informar e esclarecer o paciente pelos profissionais da medicina decorre da positivação dada pelo art. $6^{\circ}$, inciso III; art. $4^{\circ}$, inciso IV; art $8^{\circ}$, parágrafo único e art. $9^{\circ}$. Ademais, tal dever é expresso pelas regras de responsabilidade civil dos arts. 12 e 14; pelas regras vinculativas de informação como integrantes do contrato - arts. 30, 31, 36 (parágrafo único), 37 e 38 e pelas regras que garantem o amplo conhecimento do conteúdo do contrato pelo consumidor - art.46. Já a boa-fé subjetiva está presente nos arts. $4^{\circ}$, inciso III e 51 , inciso IV do mesmo diploma consumeirista. No âmbito do CC/02, o dever de informação e esclarecimento está previsto nos arts. 113, 187 e 422, decorrentes da incidência da boa-fé (BRASIL, 1990).

O Código de Ética Médica (CONSELHO FEDERAL DE MEDICINA, 1988) em seu artigo 46, atesta que: “[...] é vedado ao médico efetuar qualquer procedimento médico sem o esclarecimento e o consentimento prévios do paciente ou de seu responsável legal, salvo em iminente perigo de vida”. Os artigos 34, 53, 54, 55, 101 e 110 do CEM corroboram o entendimento de que, do ponto de vista ético, é clara a necessidade de se obter o consentimento informado do paciente nas mais diversas situações da relação médico paciente.

De acordo com Parecer do Conselho Federal de Medicina, o consentimento esclarecido não precisa ser firmado para produzir efeitos, salvo em caso de pesquisa médica ou quando tratar-se de cirurgias 
mutiladoras necessárias para preservar a vida do paciente ${ }^{3}$.

A própria classe médica demostra preocupação em documentar e, se necessário, comprovar o dever de informação ao paciente: o SIMERS - Sindicato dos Médicos do Rio Grande do Sul, tomou a iniciativa de enviar a seus filiados ao modelo de formulário de consentimento informado a ser completado pelo médico, com espaço para assinatura do paciente e dois familiares (SOUZA, 2008).

Uma vez documentado, o consentimento informado entrará para o plano da existência como fato jurídico, podendo, assim, ter efeitos jurídicos e ser utilizado nos tribunais, em eventual lide decorrente do ato médico realizado (MELLO, 2003).

Embora os médicos, a princípio, não respondam pelos riscos inerentes à atividade profissional que exercem, poderão responder caso deixem de informar ao paciente as consequências possíveis do tratamento a que serão submetidos. Somente o consentimento informado pode afastar a responsabilidade médica pelos riscos inerentes à sua atividade (CAVALIERI FILHO, 2004, p. 82).

A falta de informação ou sua insuficiência podem acarretar a perda de uma chance por parte do paciente, tendo em vista a vedação da possibilidade de escolha por um tratamento que ofereça menos riscos, ou a opção por uma conferência médica (GOGLIANO, 2009).

A inobservância de realizar o consentimento informado, no contexto da relação médico paciente, evidencia um agir culposo do profissional. Será, portanto, devida a indenização pelos danos que, eventualmente, venham a ocorrer em decorrência de ato médico que

3 O médico, pela natureza de seu trabalho, não pode garantir resultado do tratamento que faz, o que é reconhecido pelo próprio Código de Defesa do Consumidor, que o obriga a responder por responsabilidade subjetiva (determinação da culpa), quando for acusado. $\mathrm{O}$ consentimento esclarecido não precisa ser firmado para produzir efeitos, salvo em casos de pesquisa médica ou quando tratar-se de cirurgias mutiladoras necessárias para preservar a vida do paciente (CONSELHO FEDERAL DE MEDICINA, 1988). 
não seja precedido do respectivo consentimento informado. A medida da indenização será a extensão dos danos. A culpa, ainda que levíssima, obriga a indenizar (SOUZA, 2008).

Diante do exposto, faz-se necessário traçar um panorama do entendimento do Superior Tribunal de Justiça (STJ), no que tange ao consentimento informado e suas implicações em um processo de responsabilidade civil médica.

\subsection{Panorama Jurisprudencial do TJ-RS Quanto à Responsabilidade Civil Médica por Falta de Consentimento Informado}

Com o objetivo de estabelecer um panorama jurisprudencial do Tribunal de Justiça do Rio Grande do Sul, no que tange à responsabilidade civil médica por falta de consentimento informado, realizou-se consulta ao site do referido tribunal, utilizando-se as seguintes palavras chave: "consentimento informado" e "responsabilidade civil" e "médico". Foram encontrados 26 acórdãos que trataram sobre o tema. O lapso temporal da consulta transcorreu entre o mês de novembro de 2003 (ano da primeira decisão do TJ-RS sobre o assunto) e o mês de abril de 2015.

Foi realizada a coleta e análise da íntegra dos acórdãos no que tange ao entendimento do TJ-RS quanto à necessidade de consentimento informado no atendimento médico, bem como o estatuto jurídico que justifica tal necessidade.

\subsubsection{Resultados e Discussão}

Entende-se por jurisprudência a forma de revelação do Direito 
que se processa através do exercício da jurisdição, em virtude de uma sucessão harmônica de decisões nos tribunais. (REALE, 2004).

Através da análise dos 26 acórdãos coletados, observa-se que a jurisprudência do TJ-RS é pacífica no sentido de que a obrigação assumida pelo médico é de meio, devendo este utilizar-se de toda a técnica disponível para o tratamento do paciente. Tal responsabilidade depende da comprovação de culpa, a teor do disposto no art. 14, parágrafo $4^{\circ}$ do CDC. Excetuam-se, entretanto, os casos de procedimento cirúrgico plástico embelezador ${ }^{4}$ que, por unanimidade, foram considerados como obrigação de resultado, sendo atribuída ao médico responsabilidade civil subjetiva com culpa presumida.

Optamos por excluir dois acórdãos que não conheceram dos apelos quanto à alegação de ausência de consentimento informado, por constituir inovação recursal, uma vez que tal questão não foi suscitada na inicial das referidas decisões. A opção pela exclusão deve-se ao fato de que o objetivo deste trabalho é justamente identificar o posicionamento do TJ-RS no que tange à necessidade de consentimento informado no atendimento médico, o que não foi possível nos referidos acórdãos.

Destarte, da jurisprudência analisada, restaram 24 acórdãos que enfrentaram a temática do consentimento informado relacionado a demandas de responsabilidade civil médica. Destes 24 acórdãos, verificou-se uma possível relação entre os resultados das demandas como procedentes ou improcedentes, e a presença de consentimento informado como meio probatório da defesa (Tabela 1).

Tabela 1- Associação entre o resultado das demandas de responsabilidade civil médica e o uso do consentimento informado no

4 Do total de 26 acórdãos coletados, 6 deles versavam sobre cirurgia plástica embelezadora. 
atendimento médico nos 24 acórdãos analisados.

\section{Resultado}

\section{Com consentimento}

informado

Sem consentimento informado

Total

Fonte: Autores.
Procedente

12

12
Improcedente

7

5

12

Dos 24 acórdãos coletados, apenas 7 apresentavam consentimento informado como meio de prova, sendo que destes, todos foram improcedentes, ou seja, em nenhum dos casos em que restou comprovada nos autos a presença de consentimento informado no atendimento ao paciente, houve condenação por responsabilidade civil do médico.

Por outro lado, dos 17 acórdãos em que não houve a comprovação do consentimento informado no procedimento médico, 12 foram procedentes e apenas 5 improcedentes. Nos 5 acórdãos improcedentes em que não havia consentimento informado, outros meios de prova foram utilizados pelo réu, tais como: pericia, depoimento de testemunhas, prontuário médico e relatório cirúrgico, depoimento pessoal.

Analisando os 24 acórdãos que trataram sobre o tema da responsabilidade civil médica associada ao consentimento informado, foi possível identificar que 15 deles fazem referência a algum fundamento normativo em relação ao dever de informação, com a predominância do Código de Defesa do Consumidor (CDC) e do Código de Ética Médica (CEM). As 9 decisões que não indicaram fundamento normativo, embasam o "dever de informar" dos médicos através da doutrina e/ou jurisprudência citada (Tabela 2). 
Tabela 2 - Fundamentos normativos utilizados nos 24 acórdãos coletados que tratavam do tema do consentimento informado associado à responsabilidade civil médica.

\begin{tabular}{l|c}
\hline Fundamento normativo & $\begin{array}{l}\text { Acórdãos } \\
(\%)\end{array}$ \\
\hline Código de defesa do consumidor (CDC) & $12(50 \%)$ \\
\hline Código Civil (CC/02) & $4(16,66 \%)$ \\
\hline Código de Ética Médica (CEM) & $14(58,33 \%)$ \\
\hline Constituição Federal (CF/88) & $9(37,5 \%)$ \\
\hline Parecer do Conselho Federal de medicina (CFM) & $2(8,33 \%)$ \\
\hline Sem indicação normativa & $9(37,5 \%)$ \\
\hline Total & $24(100 \%)$ \\
\hline
\end{tabular}

Fonte: Autores.

Diferentemente do resultado encontrado por Pithan (2012), em que apenas 1 (um) dos acórdãos faz referência à Constituição Federal como fundamento normativo (correspondendo a $2 \%$ do total), nosso trabalho encontrou 9 acórdãos (37,5\% do total) que utilizaram normas ou princípios constitucionais para o embasamento legal das decisões.

A inobservância ao consentimento informado não caracteriza, por si só, conduta omissiva do médico, porquanto existe a necessidade de comprovação de que, do ato cirúrgico praticado decorreu algum dano físico ou abalo moral à paciente. Não havendo demonstração do dano, 
não há que se falar em responsabilidade civil. Segundo o autor:

[...] para que se caracterize a responsabilidade civil do médico, pela não obtenção do consentimento informado, deve-se estabelecer relação clara entre a falta de informação e o prejuízo final. Assim, o dano deve ser consequência da informação falha ou inexistente e esta se liga àquele por nexo de causalidade (KFOURI NETO, 2013).

Dos 24 acórdãos analisados, houve a condenação do médico por responsabilidade civil decorrente da falta de consentimento informado em 8 deles (representando 1/3 do total), apesar de não ter sido acolhida, nos referidos casos, a alegação de suposto erro médico, seja por ausência de nexo causal ou de conduta culposa por parte do profissional. A ofensa ao dever de informar por parte do médico, o dano sofrido pelo paciente e o nexo causal entre a conduta omissa do médico e o dano suportado pelo paciente foram reconhecidos nos 8 acórdãos em comento, o que acarretou a obrigação de indenizar por parte do profissional.

Nosso estudo vai ao encontro do trabalho de Pithan, que realizou pesquisa pertinente ao tema da responsabilidade civil por falta de consentimento informado na assistência médica, a partir da análise de acórdãos de seis Tribunais de Justiça estaduais brasileiros. Dos 54 acórdãos analisados, verificou-se uma possível relação entre os resultados das demandas, como procedentes ou improcedentes, e o uso do consentimento informado como meio probatório da defesa. Do total de 42 demandas procedentes (que implicaram na condenação do médico), $59,25 \%$ tramitaram sem o consentimento informado do paciente, o que corroborou o entendimento da autora de que é importante a formalização do mesmo (PITHAN, 2012). 
Estudo realizado por Garfinkel (GARFINKEL, 2007), ao analisar 910 acórdãos proferidos pelo TJ-SP, utilizando os termos "erro médico" e "responsabilidade civil", verificou que a falta de consentimento informado é algo recorrente nas ações por erro médico. A autora inclusive sugere a realização de uma pesquisa para investigar se o consentimento informado ajuda ou não a prevenir ações judiciais - objetivo este do presente trabalho.

\subsection{Panorama Jurisprudencial do STJ nos Casos de Responsabilidade Civil Médica por Falta de Consentimento Informado}

Com o objetivo de traçar um panorama jurisprudencial do Superior Tribunal de Justiça acerca da responsabilidade civil médica por falha no dever de informar, foi realizada consulta à página do referido tribunal, através de acesso a base de dados na internet, utilizando a combinação dos seguintes descritores: "consentimento informado" e "responsabilidade civil" e "médico". Foram encontrados quatro acórdãos que trataram sobre o tema. $\mathrm{O}$ lapso temporal da coleta transcorreu entre o período de dezembro de 2002 (ano da primeira decisão do STJ sobre o assunto) e o mês de fevereiro de 2012.

Coletou-se e analisou-se a íntegra dos acórdãos no que se refere ao entendimento do STJ quanto à necessidade de consentimento informado no atendimento médico, bem como estatuto jurídico aplicável.

\subsubsection{Resultados e Discussão}

Em 2002, acórdão do STJ cujo relator foi o Ministro Ruy 
Rosado de Aguiar, manteve a condenação do médico ao pagamento de indenização por danos materiais e morais devido à realização de cirurgia para correção de perda de visão, em que a cura prometida nunca foi obtida. Tal condenação deveu-se a conduta negligente a imprudente do médico, que não cumpriu com o dever de informação. Em sua fundamentação, o relator reafirmou o dever ético dos médicos de informar o paciente sobre as consequências da cirurgia, bem como a conveniência da intervenção, resultados, expectativas e possibilidades de êxito ou de agravamento (BRASIL, 2002b).

Ainda ano de 2002, o STJ reconheceu a responsabilidade civil do médico por danos causados a uma paciente que se submeteu à intervenção cirúrgica oftalmológica e restou com a visão irremediavelmente comprometida. A responsabilização fundamentou-se na falta cometida pelo médico que deixou de informar a paciente sobre os riscos e possíveis consequências do procedimento cirúrgico. Os magistrados defenderam a aplicação não apenas das regras de consumo, mas também das exigências éticas que regulam a relação médico - paciente (BASIL, 2002c). A importância do consentimento informado é destacada pelo Relator, Ministro Ruy Rosado de Aguiar, ao inferir que:

A despreocupação do facultativo em obter do paciente seu consentimento informado pode significar-nos casos mais graves - negligência no exercício profissional. As exigências do princípio do consentimento informado devem ser atendidas com maior zelo na medida em que aumenta o risco, ou o dano, ou diminui a possibilidade de êxito. Nas circunstâncias dos autos, o dever de informação antes e depois da cirurgia não foi cumprido (BRASIL, 2002c).

Segundo Goldim: “[...] a perspectiva da bioética é necessária, pois 
amplia a discussão do consentimento informado para além dos aspectos meramente legais" (GOLDIM, 2002). A bioética pode ser considerada como um dos instrumentos de releitura da relação médico - paciente, tendo em vista que esta nova ciência busca proporcionar um espaço para encontrar soluções aos complexos problemas éticos e jurídicos (BORGES, 2014, p. 86). Neste sentido, infere-se que o consentimento informado tem como base os fundamentos éticos e jurídicos, que estão muito próximos e norteados por princípios morais, leis e regulamentos comuns (BAÚ, 2000).

A julgar, em 2010, demanda de responsabilidade civil por erro médico em cirurgia plástica estética (mamoplastia e lipoaspiração), o STJ considerou tal procedimento cirúrgico como obrigação de resultado (BRASIL, 2010). Isto porque o cirurgião assume verdadeiro compromisso pelo efeito embelezador prometido. Entretanto, ressaltou a Relatora, Min. Nancy Andrighi, que a responsabilidade do profissional permanece subjetiva, cabendo a ele comprovar que o dano ocorreu por fatores externos, alheios à sua atuação durante a cirurgia. Destacou-se a incidência do CDC na relação médico-paciente, sobretudo dos art. $6^{\circ}$, inc. III e art. 14 do referido diploma legal. A decisão confirmou o caso fortuito como excludente de responsabilidade do médico (afastando o nexo de causalidade entre a conduta e o dano), reafirmou a importância do termo de consentimento informado, assinado pela paciente, para o deslinde da questão, e, por conseguinte, isentou o profissional de responsabilidade civil médica. Com relação ao termo de consentimento informado, o acórdão supracitado infere que: "[...] age com cautela e conforme os ditames da boa-fé objetiva o médico que colhe a assinatura do paciente em 'termo de consentimento informado', de maneira a alertá-lo acerca de eventuais problemas que possam surgir durante o pós-operatório" 
(BRASIL, 2010).

Ademais, a relatora, aduz que:

[...] não se trata de atribuir ao "termo de consentimento informado" a capacidade de excluir o dever do médico de indenizar o paciente por eventuais danos provocados por negligência, imprudência ou imperícia. O documento assinado pela recorrida somente comprova a boa-fé que orientou-a durante a relação com o paciente, enumerando os benefícios e complicações normalmente diagnosticados na intervenção a que se submeteu o recorrente- inclusive as hipóteses de caso fortuito, que escapam ao controle da ciência médica (BRASIL, 2010).

De forma majoritária, os juristas brasileiros defendem a aplicação do CDC nas relações médico-paciente. ${ }^{5}$ Busca-se a proteção do consumidor, que é a parte mais vulnerável e que se encontra em condições de desigualdade em relação ao fornecedor de produtos ou serviços (MIRAGEM, 2007, p. 71).

A relação estabelecida entre o paciente e o médico é contratual, sob a qual incide o CDC (BRASIL, 1990). Entretanto, a autora ressalva que tal relação deverá ser analisada conjuntamente com um núcleo de deveres extrapatrimoniais. Entre esses deveres jurídicos, estão os deveres de informação "[...] de exponencial relevância no âmbito das relações jurídicas de consumo[...]”, decorrentes do princípio da boa-fé objetiva ou da própria legislação (PITHAN, 2005).

5 Nesse sentido, os seguintes autores: Cláudia Lima Marques, Bruno Miragem, Sérgio Cavalhieri Filho, etc. 
Um quarto acórdão (BRASIL, 2012), no ano de 2012, reafirmou a decisão do Tribunal de origem, que firmou a sua conclusão no sentido de que não houve, por parte do médico, advertência à paciente quanto aos riscos da cirurgia plástica estética de reconstrução da mama. Ademais, o médico não provou a ocorrência de caso fortuito - alegado por este na inicial. O Recurso Especial não foi conhecido pelo STJ, mantendo-se a condenação do médico por danos materiais e morais, baseada em duas premissas: a) não houve consentimento informado; b) o médico não logrou comprovar caso fortuito.

Os resultados podem ser resumidos conforme a tabela 3 abaixo: Tabela 3- Associação entre o resultado das demandas de responsabilidade civil médica e o uso do consentimento informado no atendimento médico nos 4 acórdãos analisados.

\section{ACÓRDÃo}

OUT / 2002

DEZ / 2002

AGO / 2010

FEV / 2012
CONSENTIMENTO

INFORMADO

AUSENTE

AUSENTE

PRESENTE

AUSENTE
CONDENAÇÃO DO

MÉDICO

SIM

SIM

NÃO

SIM

Fonte: Autores.

Por meio de análise da tabela acima, apesar desse estudo abranger um número reduzido de acórdãos, ainda que estes representem o total de decisões proferidas pelo STJ, referentes ao tema, pode-se cogitar de uma possível relação entre a ausência de consentimento informado e 
a responsabilização civil do médico.

Há uma discussão na doutrina a respeito da necessidade do consentimento informado ser impresso, escrito e assinado. Kfouri Neto defende que: "[...] o consentimento deverá ser documentado e registrado, sob pena de o profissional ver-se impossibilitado de provar a efetiva obtenção do assentimento do enfermo - fato que também poderá redundar em consequências gravosas no âmbito da responsabilidade civil" (KFOURI NETO, 2002, p. 297). Apenas um dos acórdãos analisados (o de relatoria da ministra Nancy Andrighi) trouxe de forma expressa a questão da assinatura de um "termo de consentimento informado" como expressão da boa-fé objetiva por parte do médico.

\section{CONCLUSÃO}

Pelo exposto, pode-se concluir que a caracterização da responsabilidade civil médica depende fundamentalmente da prova da culpa do profissional liberal, ônus que cabe, geralmente, a quem alega o dano - o paciente. Cabe ressaltar que, nos casos de obrigação de resultado (como no caso de cirurgias plásticas embelezadoras), a culpa pode ser presumida, cabendo ao médico desincumbir-se desse ônus, trazendo a juízo provas de que não agiu com negligência, imprudência ou imperícia. Ademais, nos casos em que for reconhecida a hipossuficiência do paciente, bem como a verossimilhança das alegações, poderá também haver inversão do ônus da prova, conforme previsão do Código de Defesa do Consumidor, cabendo ao médico exonerar-se da responsabilidade pelos danos causados ao paciente.

Através da análise da jurisprudência do TJ-RS e do STJ, verificou-se que o consentimento informado tem base jurídica a partir do 
CDC, do CC/02, do CEM, da CF/88, de Parecer do CFM, e da doutrina pertinente ao tema da responsabilidade civil médica.

Aausência do dever de informar poderá ensejar a responsabilização do médico, mesmo quando afastada a culpa do profissional. Isso devese ao fato de que a relação médico-paciente pode ser considerada pela doutrina e jurisprudência majoritárias uma relação de consumo, sendo que o direito à informação é um direito básico do consumidor, previsto não apenas no $\mathrm{CDC}$, mas também no $\mathrm{CC} / 02$, que inclusive traz expresso o princípio da autonomia da vontade - um dos princípios norteadores do consentimento informado. Além disso, princípios constitucionais como o do direito à vida e à liberdade também servem para justificar a necessidade do consentimento informado na relação médico-paciente.

Nosso estudo verificou uma possível relação entre a ausência de consentimento informado e a consequente responsabilização civil do médico por descumprimento do dever de informar, o que indicaria que a obtenção do consentimento informado na relação médico-paciente ajuda a prevenir ações judiciais por responsabilidade civil médica.

Apesar da legislação não prever que o consentimento informado deva ser expresso através de um termo de consentimento informado, sugerimos que esta prática ocorra, a fim de que este consentimento escrito e assinado pelas partes possa ser utilizado como prova em eventual demanda por responsabilidade civil médica.

\section{REFERÊNCIAS}

AGUIAR JÚNIOR, Ruy Rosado de. Responsabilidade civil do médico. Revista Jurídica, Salvador, ano 45, n. 231, p. 122-147, 1997.

BARBOZA, Heloisa Helena. Princípios da bioética e do biodireito. 
Bioética, Brasília, v. 8, n. 2, p. 209-216, 2000.

BAÚ, Marilise Kostelnaki. Capacidade jurídica e consentimento informado. Bioética, Brasília, v. 8, n. 2, p. 285-296, 2000.

BAUMAN, Zigmunt. O mal-estar da pós-modernidade. Tradução de Mauro Gama, Cláudia Martinelli Gama. Rio de Janeiro: Jorge Zahar, 1998.

BECK, Ulrich. La sociedad del riesgo. Tradução de Jorge Navarro. Barcelona: Paidós, 1998.

BENJAMIN, Antônio Herman V.; MARQUES, Claudia Lima; BESSA, Leonardo Roscoe. Manual de direito do consumidor. 4. ed. São Paulo: Revista dos Tribunais, 2012.

BHABHA, Homi K. O local da cultura. Tradução de Myriam Ávila. Belo Horizonte: UFMG, 2005.

BORGES, Gustavo. Erro médico nas cirurgias plásticas. São Paulo: Atlas, 2014.

BRASIL. Lei $\mathbf{n}^{0} \mathbf{8 . 0 7 8}$, de 11 de setembro de 1990. Dispõe sobre a proteção do consumidor e dá outras providências. Disponível em: $<$ http:// www.planalto.gov.br/ccivil_03/leis/L8078.htm>. Acesso em: 17 mar. 2016.

BRASIL. Lei $\mathbf{n}^{\mathbf{0}} \mathbf{1 0 . 4 0 6}$, de 10 de janeiro de 2002. Institui o Código Civil. 2002a. Disponível em: <http://www.planalto.gov.br/ccivil_03/ leis/2002/L10406.htm>. Acesso em: 17 mar. 2017.

BRASIL. Superior Tribunal de Justiça. Recurso Especial n $\mathbf{n}^{\mathbf{1}} \mathbf{1 . 1 8 0 . 8 1 5 -}$ MG. Relatora Ministra Nancy Andrighi, 19 ago. 2010.

BRASIL. Superior Tribunal de Justiça. Recurso Especial n ${ }^{\circ}$ 436.827-SP. 
Relator Ministro Ruy Rosado de Aguiar. Brasília, 1 out. 2002b.

BRASIL. Superior Tribunal de Justiça. Recurso Especial no ${ }^{\mathbf{4} 67.878-R J}$. Relator Ministro Ruy Rosado de Aguiar. Brasília, 5 dez. 2002c.

BRASIL. Superior Tribunal de Justiça. Recurso Especial $\mathbf{n}^{\mathbf{0}}$ 985.888-SP. Relator Ministro Luis Felipe Salomão. Brasília, 16 fev. 2012.

CAVALIERI FILHO, Sérgio. A responsabilidade médica e o dever de informar. Revista da EMERJ, Rio de Janeiro, v. 7, n. 28, p.82, 2004.

. Programa de responsabilidade civil. 11. ed. São Paulo: Atlas, 2014.

CLOTET, Joaquim. Bioética: uma visão panorâmica. Porto Alegre: EDIPUCRS, 2005.

O consentimento informado nos Comitês de Ética em pesquisa e na prática médica: conceituação, origens e atualidade. Bioética, Brasília, v. 3, n. 1, p. 51-59, 1995.

CONSELHO FEDERAL DE MEDICINA. Resolução CFM n ${ }^{0} \mathbf{1 . 2 4 6}$, de 8 de janeiro de 1988. Dispõe sobre o Código de Ética Médica. Disponível em: $<$ http://www.portalmedico.org.br/include/codigo_etica/ codigo_etica2.asp>. Acesso em: 17 mar. 2017.

COSTA, S. I. F.; PESSINI, L. Ética e medicina no limiar de um novo tempo: alguns desafios emergentes. In: LIMA FILHO, A. A.; POZZOLI, L. (Org.). Ética no novo milênio: "busca do sentido da vida". 3. ed. São Paulo: LTR, 2004. p. 187-214.

FARAH, Elias. Atos médicos - reflexões sobre suas responsabilidades. Revista do IASP, São Paulo, v. 13, n. 25, p. 140-196, jan./jun. 2010. 
GARFINKEL, Ana. Responsabilidade civil por erro médico segundo a jurisprudência do tribunal de justiça do estado de São Paulo. Revista Direito FGV, São Paulo, v. 3, n. 21, p. 37-58, 2007.

GAUER, Ruth M. Chittó. O reino da estupidez e o reino da razão. Rio de Janeiro: Editora Lumen Juris, 2006.

GOGLIANO, Daisy. O consentimento esclarecido em matéria de bioética: ilusão de exclusão de responsabilidade. Revista da Faculdade de Direito [Da] Universidade de São Paulo, São Paulo, v. 104, p. 509-547, jan./ dez. 2009.

GOLDIM, José Roberto. O consentimento informado numa perspectiva além da autonomia. Revista AMRIGS, Porto Alegre, v. 46, n. 3, p. 109$116,2002$.

HALL, Stuart. A identidade cultural na pós-modernidade. Tradução de Tomaz Tadeu da Silva e Guacira Lopes Louro. 10. ed. Rio de Janeiro: DP\&A, 2005.

KFOURI NETO, Miguel. Responsabilidade civil do médico. 8. Ed. São Paulo: Revista dos Tribunais, 2013.

. Culpa médica e ônus da prova: presunções, perda de uma chance, cargas probatórias dinâmicas, inversão do ônus probatório e consentimento informado, Revista dos Tribunais, 2002.

MACHADO, Diego Carvalho. Autonomia privada, consentimento e corpo humano: para a construção da própria esfera privada na era tecnológica. Revista Trimestral de Direito Civil: RTDC, Rio de Janeiro, v. 10, n. 37, p. 17-52, jan./mar. 2009.

MARQUES, Claudia Lima; BENJAMIN, Antônio Herman V.; MIRAGEM, Bruno. Comentários ao código de defesa do consumidor. 3. ed. São Paulo: Revista dos Tribunais, 2010. 
MARTINS-COSTA, Judith. A universidade e a construção do biodireito. Bioética, Brasília: Conselho Federal de Medicina, v. 8, n. 2, p.230, 2000.

MELLO, Marcos Bernardes. Teoria do fato jurídico: plano da existência. 12. ed. São Paulo: Saraiva, 2003.

MIRAGEM, Bruno. Responsabilidade civil médica no direito brasileiro. Revista de Direito do Consumidor, São Paulo, n. 63, p. 53-91, jul./ set. 2007.

NESRALLA, Ivo A.; PRATES, Paulo R. As emoções da cirurgia do coração. Porto Alegre: AGE, 2014.

NEVES, Camila. Responsabilidade civil do cirurgião plástico: obrigação de meio ou de resultado. Porto Alegre: Stampa, 2009.

PITHAN, Lívia Haygert. O consentimento informado como exigência ética e jurídica. In: CLOTET, Joaquim. Bioética: uma visão panorâmica. Porto Alegre: EDIPUCRS, 2005.

. O consentimento informado no Poder Judiciário brasileiro. Revista da AMRIGS, Porto Alegre, v. 56, n. 1, p. 87-92, jan./mar. 2012.

REALE. Miguel. Lições preliminares do direito. 27. ed. São Paulo: Saraiva, 2004.

SGRECCIA, Elio. Manual de bioética. 2. ed. São Paulo: Loyola, 2002.

SOTTO, Débora. O dever de informar do médico e o consentimento informado do paciente. Medidas preventivas a responsabilização pela falta ou deficiência de informação. Revista Jus Nagigandi, Teresina, ano 8, n. 178, 2003.

SOUZA, Neri Tadeu Camara. Erro médico e consentimento informado. 
Revista Jurídica Empresarial, Porto Alegre, v. 1, n. 3, p. 77-87, jul./ ago. 2008.

Como citar: BORGES, Gustavo Silveira. MOTTIN, Roberta Weirich. Erro médico e consentimento informado: panorama jurisprudencial do TJRS e do STJ. Revista do Direito Público, Londrina, v. 12, n. 1, p.1547, abr. 2017. DOI: 10.5433/24122-107817-1X.2017v17n1p15. ISSN: 1980-511X.

Recebido em: 24/12/2015

Aprovado em: 12/01/2017 